\title{
FERTILITY, ETHNICITY, AND EDUCATION
}

\section{IN THE DEMOCRATIC REPUBLIC OF THE CONGO}

\author{
David Shapiro ${ }^{1} \&$ Basile O. Tambashe ${ }^{2}$ \\ ${ }^{1}$ Department of Economics, Pennsylvania State University \\ United States \\ dshapiro@psu.edu \\ ${ }^{2}$ Department of Population Sciences and Development, University of Kinshasa \\ Democratic Republic of the Congo \\ btambashe@outlook.com
}

\begin{abstract}
In the mid-1950s, a massive survey in the present Democratic Republic of the Congo revealed sharp ethnic fertility differentials. With the vast majority of women never having been to school, women's education was not, then, pertinent to fertility. Over the succeeding decades, women increasingly went to school, especially in Kinshasa. This led to lower fertility in the capital, particularly for women with secondary schooling. At the same time, fertility differences by ethnic group diminished in the city. This paper examines fertility differences by education and by ethnicity in the entire country, distinguishing Kinshasa, other urban places, and rural areas. We find that, over all, the increased importance for fertility of education and reduced importance of ethnicity witnessed in Kinshasa is also apparent for the entire country. Regarding the sources of ethnic differences in fertility, the findings support the social characteristics hypothesis in cosmopolitan Kinshasa and the cultural hypothesis elsewhere.
\end{abstract}

Keywords: Fertility, fertility differentials, ethnicity, education, Democratic Republic of the Congo.

\section{Introduction}

This paper explores fertility and fertility differences in the Democratic Republic of the Congo (DRC) over the past 60 years. The DRC is the third most populous country in sub-Saharan Africa, and the United Nations estimate of its current total fertility rate, 6.15 children per woman (United Nations, 2015), ranks it as having the $6^{\text {th }}$-highest fertility in the world. However, we will argue below that the U.N. estimate is too low, and that the DRC more likely ranks as tied for second as having the highest fertility worldwide. In any case, it is a big country with a very high level of fertility.

In the mid-1950s, a massive survey in what is now the DRC provided the first national fertility estimates, which revealed very sharp ethnic fertility differentials in the country (Romaniuk, 1967). The northern provinces, which were part of a broader central African infertility belt (Retel-Laurentin, 1974), had especially low fertility and high proportions of childless women; this was largely attributable to differential exposure to sexually transmitted infections (STIs) (Romaniuk, I96I, 1967), presumably reflecting the diversity of cultural mores and practices. In addition, and in contrast to what one normally anticipates, in the mid-1950s fertility was higher in urban places (and especially in the capital, Leopoldville, now Kinshasa, and in Elisabethville, now Lubumbashi) as compared to rural places.

At that time, the vast majority of women of reproductive age had never been to school, so women's education was not a factor pertinent to fertility. Over the succeeding decades, however, particularly following independence in 1960, women increasingly went to school and advanced in school, especially in Kinshasa, and to a lesser degree, in smaller urban places. Women's increased educational attainment was associated with lower fertility in Kinshasa, particularly for women who had at least reached the secondary school level (Shapiro, 1996; Shapiro and Tambashe, 2003; Shapiro, 2015). This is evident as well in data from the recent Demographic and Health Surveys. At the same time, fertility differences by ethnic group have diminished in the city (Sala-Diakanda, 1980; Tambashe, 1984; and Shapiro, 20I0). 
In this paper, we examine fertility differences by education and by ethnicity in the country as a whole. We seek to determine if the increased importance of education for fertility and reduced importance of ethnicity for fertility that has been observed in Kinshasa is also apparent for the entire country. We carry out analyses distinguishing Kinshasa from other urban places and for those in rural areas as well. We also examine several factors that contribute to fertility differences by ethnic group and by education.

In the next section of this paper, we discuss the theoretical framework and provide a literature review, including examination of the central findings on fertility and ethnicity from the mid-1950s, and discussion of more recent evidence from Kinshasa indicating that educational attainment has supplanted ethnicity as an important factor influencing fertility. Data and Methods are described in section 3. The Results and Discussion section begins with a presentation of the seven major broad ethnic groups in the DRC that are identified in the data, and their location within the country. We then examine the current aggregate fertility levels (total fertility rates) by ethnic group and by educational attainment, and subsequently analyze national-level microdata on fertility (children ever born) in relation to education and ethnicity, with separate estimates for Kinshasa, other urban places, and rural areas. These analyses are based on the most recent Demographic and Health Survey (20/3-I4) carried out in the DRC. The latter part of the Results and Discussion section examines several factors that may contribute to the observed differences in fertility by ethnic group and then by a detailed set of education groups. This is followed by a Summary and Conclusions section.

\section{Theoretical Framework and Literature Review}

The theoretical framework that underlies this research is the Easterlin framework for fertility analysis (Easterlin, 1976; Easterlin and Crimmins, 1985). Within the context of this framework, women's education has multiple pathways by which it is likely to influence fertility. These pathways were explored by Cochrane (1979), although her work had very little on sub-Saharan Africa due to lack of data. With the availability of Demographic and Health Survey (DHS) data, that situation has changed, and considerable research has emerged documenting linkages between education and fertility.

For example, women's schooling has been shown to influence ideal number of children (desired family size) and hence the demand for children (Castro Martin, 1995; Bongaarts, 2010; Westoff et al., 2013; Muhoza et al., 2014; Kim, 2016). Women with greater schooling tend to delay marriage and the onset of childbearing (United Nations, 1995; Shapiro 3254 and Gebreselassie, 20I4), and they are more likely to use contraception and effective contraception than their lesser-educated counterparts (Bongaarts, 2010; Westoff et al., 2013; Kim, 2016). At the same time, they are less inclined to engage in prolonged breastfeeding or practice extended post-partum abstinence (Jejeebhoy, 1986; United Nations, 1995; Cleland and Jejeebhoy, 1996). In addition, bettereducated women tend to experience lower infant and child mortality (Tabutin and Akoto, 1992; Jayne, 1997; Mogford, 2004), and this has also contributed to fertility decline in the region (Shapiro, 2012; Shapiro and Tenikue, 2017).

Within the Easterlin framework, ethnic fertility differences would be seen as reflecting differences in tastes and preferences. Fertility aspirations and preferences would be shaped by community norms, values, attitudes, and practices (Kollehlon, 1989). Several studies seeking to tease out the underlying factors behind observed ethnic fertility differentials typically combined competing perspectives: (a) the cultural perspective, which explains ethnic fertility differences in terms of differences in cultural values and community practices governing childbearing; (b) the psychosocial perspective, which complements the cultural perspective and associates ethnic fertility differences with differences in individual attitudes and preferences with regard to childbearing; (c) the structural perspective, which suggests that ethnic fertility differentials are reflective of the relative position of an ethnic group within the stratification system in the society, in terms of its minority vs. majority status within the society; and (d) the assimilationist perspective, which associates ethnic differences in fertility with differences in individual background characteristics and suggests that ethnic differentials would gradually vanish as ethnic groups get assimilated into the prevailing majority culture (Gastardo-Conaco et al., 1986; Tan and Soeradji, 1986).

This framework guided the seminal work on ethnicity and fertility in five south Asian countries back in the 1980s (e.g., see Gastardo-Conaco et al., 1986; Tan and Soeradji, 1986). In sub-Saharan Africa, three main explanations of the effect of ethnicity on fertility have been formalized through testing one or more of the following key hypotheses: the socioeconomic hypothesis, the cultural hypothesis, and the minority group status hypothesis (Kollehlon, 1989; Nahmias, 2007). And in line with the Davis and Blake (1956) framework, the ethnicity effect on fertility is thought to be mediated through the proximate determinants of fertility.

Previous research on Kinshasa (Shapiro and Tambashe, 2003) and elsewhere in sub-Saharan Africa (Njogu, 1989; Kritz and Makinwa-Adebusoye, http://aps.journals.ac.za 
1994, 1998; Bauni et al., 1999; Johnson-Hanks, 2003; Nahmias, 2007; Bauni et al., 20I I) has documented ethnic group differences in fertility, fertility preferences, premarital fertility (Garenne and Zwang, 2006; Johnson-Hanks, 2003), and in the proximate determinants of fertility. With regard to the sources of ethnic differences in fertility, findings from studies in Nigeria (Kollehlon, 2003; Brunette, 1996) and Cameroon (Johnson-Hanks, 2003) were found to be consistent with the cultural hypothesis as well as the socioeconomic hypothesis. Though the magnitude of observed ethnic differences is generally reduced after background and demographic characteristics are controlled for, the net differences often remained statistically significant. While Kollehlon (1989) in her work in Liberia did not find support for the minority group status hypothesis, Nahmias (2007) reported tentative evidence for this hypothesis in comparing fertility among select trans-national ethnic groups in West Africa. In Nigeria and Benin, the Fulani are a minority whose fertility was found to be higher in comparison to that of non-Fulani. By contrast, in Mali and Guinea where they represent a greater share of the population, Fulani fertility was found to be lower compared to non-Fulani fertility. Similarly, the Malinke of Guinea, where they are a minority, had much higher fertility in comparison to that of nonMalinke than the Malinke vs. non-Malinke in Mali, where they are an overwhelming majority (Nahmias, 2007).

Of particular note is the tendency suggested from a multi-country study on fertility and ethnicity in less developed countries (Entwisle and Mason, 1990) that, in countries where ethnic fertility differentials are observed, the differences were distinctly significant at the early stages of the reproductive life (defined in terms of age at first birth or early fertility, i.e., children born before the mother reached age 30), and not at the later phase (defined as children born after the mother reached age 30 or later fertility). This lends support to the notion that specific ethnic norms and practices may be instrumental in pacing the onset of sexual activity as well as the entry into marital life and subsequently into motherhood. Other practices that are culturally shaped or prescribed and may affect fertility directly or indirectly include but are not limited to postpartum abstinence, sexual promiscuity, coital frequency, and extended breastfeeding (Nahmias, 2007).

\section{Fertility and Ethnicity in the 1950s}

From 1955-1957, the government of the then Belgian Congo undertook the first nation-wide survey. The survey showed substantial differences in fertility across the six provinces, with birth rates in the 26 districts as high as 60 per thousand and as low as 21 per thousand (Romaniuk, 1968, Table 6.49). Similarly, total fertility rates in these districts ranged from lows of 2.9 and 3.2 to highs of 8.3 to 8.5 children per woman (Romaniuk, 1968, Table 6.48). Ordinarily, one would expect fertility in natural-fertility populations like these to be high, with only modest variation. Fertility overall was estimated at 5.9 , and urban places had higher fertility than rural places with the cities of Leopoldville and Elisabethville having estimated TFRs of 7.5 and 8.3, respectively.

Maps I and 2 show the TFRs for the six provinces and for the 24 districts, respectively, for which data were available. These maps clearly show that in the northern provinces and in many of the northern districts, in particular, fertility was unusually low. This low fertility was driven by high rates of sterility, which Romaniuk (196I, 1967) linked to the high incidence of STIs. Differing cultural mores and practices among the different ethnic groups - most notably the practice of sexual hospitality among some ethnic groups - resulted in diffusion of STls and hence some groups and areas having quite low fertility while others had very high fertility. Indeed, the low-fertility northern provinces were part of a broader central African infertility belt across much of west and central Africa in which fertility was especially low (Retel-Laurentin, 1974). 
Map I. Total Fertility Rates by Province, 1955-57
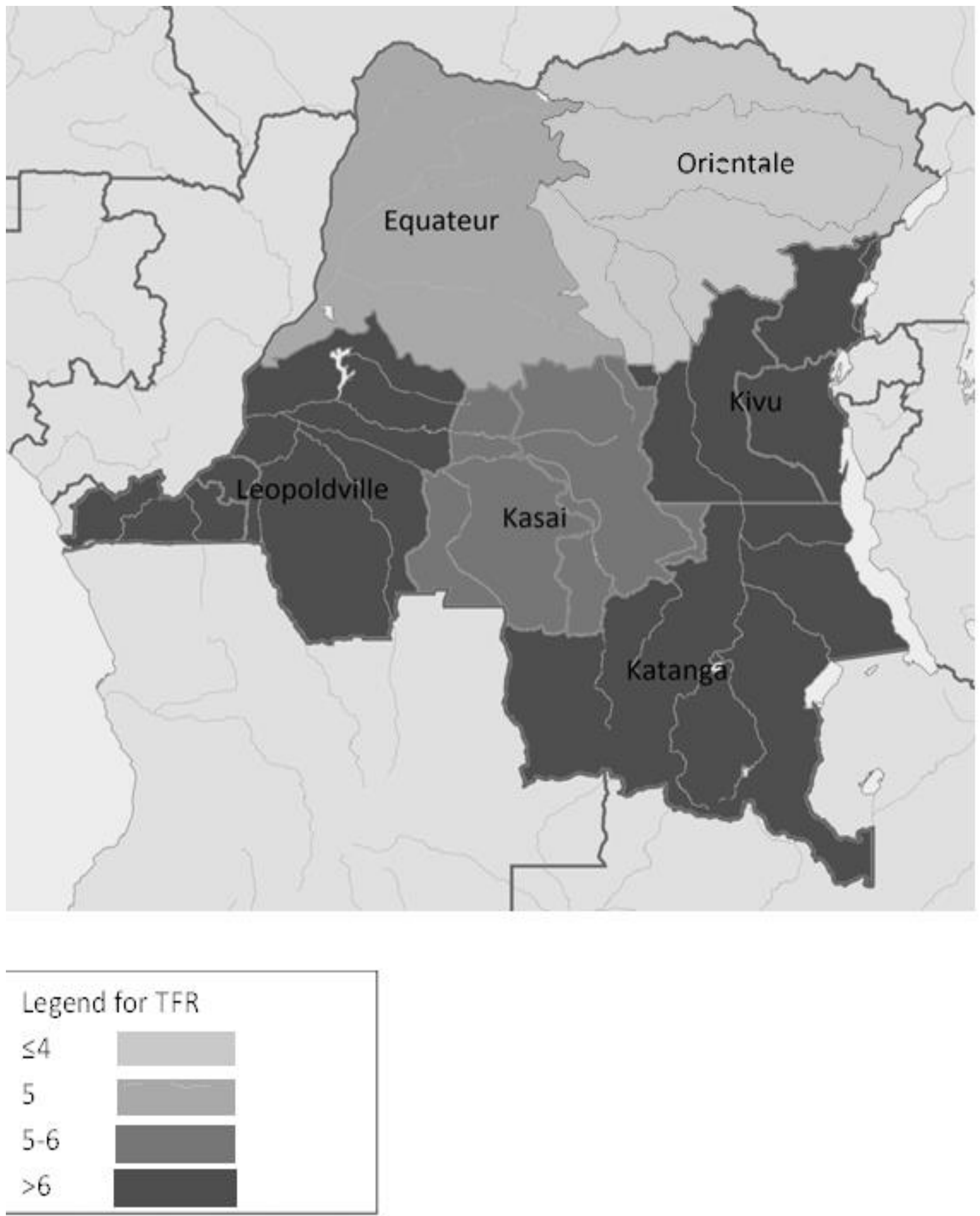


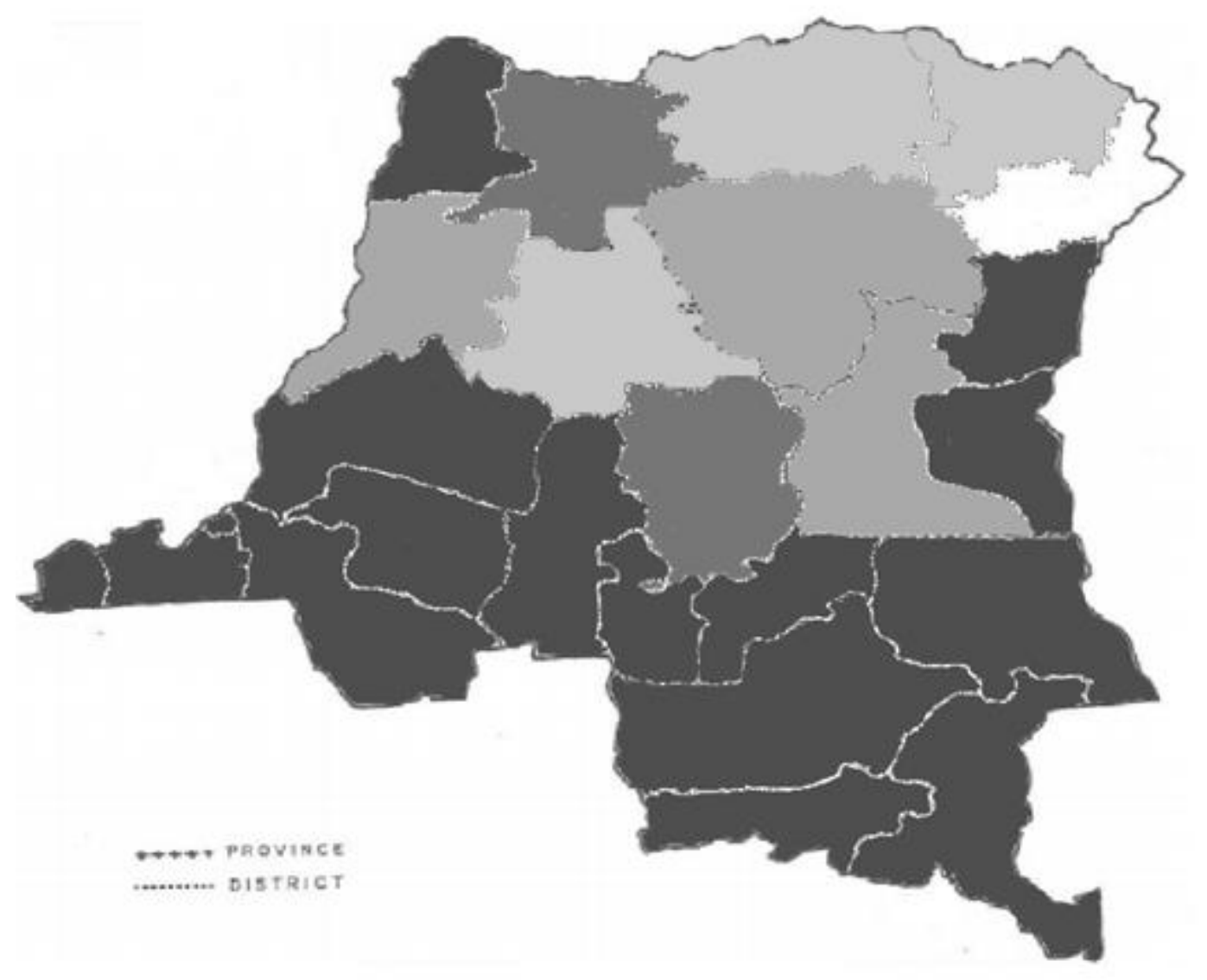

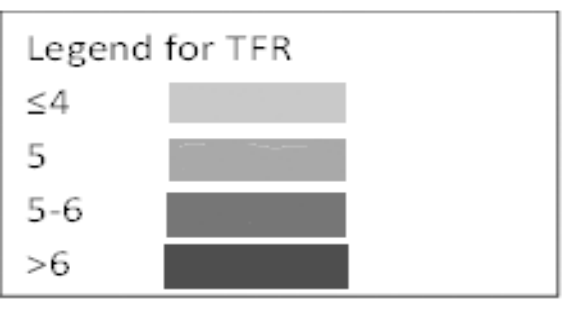

In most of the country, region of residence is closely linked to ethnic group. This in part reflects the ethnic settlement of the population predating even the colonial era. The cities, and especially the capital, Leopoldville, were where different ethnic groups lived together, but even here fertility differentials among ethnic groups could often be traced back to their regions of origin. For example, Figure I shows that among women in Kinshasa (Leopoldville) in 1955, those from the Mongo ethnic group from the north had especially low fertility, while the two Bakongo groups, from what is now Kongo Central province in the southwest of the country, had particularly high fertility. 'The "Luba, related" group in the figure had fertility that was slightly below average for the city. 


\section{Fig. 1. General Fertility Rates by Broad Ethnic Group in Kinshasa, 1955}

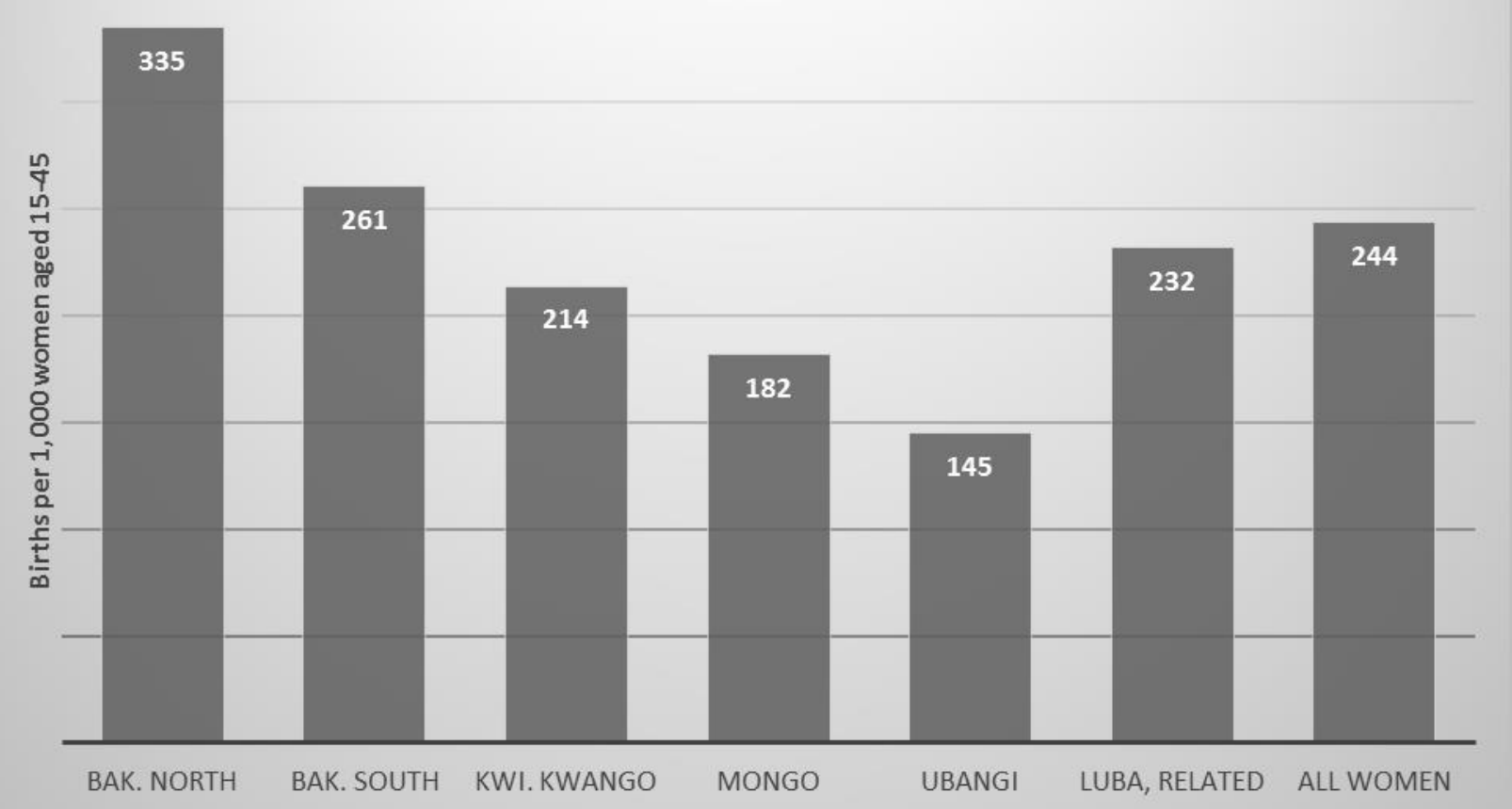

Fertility, Ethnicity, and Education in the 1970s and Beyond

Following the survey from the 1950s, the next national-level data collection operation was not until the 1984 Census. However, in the latter part of the 1970s a broad-based survey covering the western half of the country was undertaken and showed evidence of narrowing of fertility differentials by ethnic group and a slight increase in overall fertility (Sala-Diakanda, 1980; Tabutin, 1982). This narrowing as well as the increased fertility were both attributed to successful public health campaigns against STIs in affected regions. Most notably, fertility in the Equateur and Tshuapa districts of Equateur province (home to the Mongo and related Mongo-like people) had increased substantially since the mid-1950s, while infertility in these two districts had declined sharply (République du Zaire et al., 1978).

By the mid-1970s, women's education had begun to expand substantially, but educational attainment did not appear to have had much impact on fertility. For example, despite the fact that median educational attainment of women of reproductive age in Kinshasa had increased to about 5 years of schooling from none (Shapiro and Tambashe, 2003), overall fertility was estimated to be unchanged in the city (SalaDiakanda, 1980). Subsequent work (Shapiro, 1996; Shapiro and Tambashe, 2003; Shapiro, 2015) showed that the impact of education on fertility does not really emerge until the secondary schooling level, and in the mid-1970s, even in Kinshasa, most women of 3258 reproductive age (about 75 percent) (Shapiro and Tambashe, 2003) had less than secondary-level schooling.

Data from the 1984 Census showed that fertility had increased in the two historically low-fertility provinces of the 1950s, Equateur and Orientale, by 20-22 percent since the 1950s, with TFRs of 6.I and 4.8, respectively. Kasai-Oriental province, whose northern district Sankuru had somewhat low fertility in the 1950s, saw a 30 percent increase in its TFR, to 7.4 (Shapiro et al., 2017). Nationally the TFR was estimated at 6.7, but there is evidence suggesting that fertility in Kinshasa was substantially overestimated (Shapiro and Tambashe, 2003, pp. 50-52; Shapiro et al., 2017), and hence estimated national fertility was likely less than 6.7.

A small-scale survey of fertility in Kinshasa carried out in 1990 found a TFR for the city of about 5.7, almost 25 percent lower that the estimates from the mid-1950s and mid-1970s. The survey also documented the growing role of women's educational attainment as a factor contributing to fertility decline. In particular, as noted earlier, schooling at the secondary level and above was associated with distinctly lower fertility (Shapiro, 1996). At the same time, examination of fertility differences in Kinshasa showed that the differentials by educational attainment were distinctly larger than those by ethnic group (Shapiro and Tambashe, 2003), suggesting that education had supplanted ethnicity in the city as an important driver of fertility behavior.

http://aps.journals.ac.za 
Data from the first DHS in the DRC, in 2007, documented that fertility in Kinshasa had continued to decline considerably, to a level of only about half of its level of 7.5 that prevailed from the mid-1950s to the mid-1970s (Shapiro, 2015). By contrast, however, fertility had remained high elsewhere in the country. In effect, fertility transition was evident in Kinshasa, but the rest of the country was largely pretransitional (Romaniuk, 20II; Shapiro et al., 2017).

The second DHS in the DRC, carried out in 201314 , indicated that at the national level the total fertility rate had increased from 6.3 to 6.6. The same trend emerged in Kinshasa, with the TFR increasing to 4.2 from its previous level of 3.7 in 2007, suggesting a stall in the city's fertility decline during the 6-7 years following the first DHS. We note that the DHS estimate for 2013-I4 is substantially higher than the current U.N. estimate of 6.15 (United Nations, 20I5). Other things equal, the current DHS estimate implies that the DRC is essentially tied with Somalia for second place, behind Niger, as the countries with the highest fertility worldwide.

\section{Data and Methods}

The data used in the analyses here are from the 2013-14 Demographic and Health Survey of the DRC. As for methods, we first use the DHS data to identify seven major ethnic groups that can be identified in the data, and their geographic location. The number of sample cases for these ethnic groups ranges from I,594 to 5,046. We then examine education, ethnicity, and fertility in the DRC as of 2014, using cross-tab tables that show total fertility rates by ethnic group and by education group, overall and in relation to place of residence. This is followed by multivariate analyses of individual data on fertility, with children ever born as our dependent variable. Those analyses control for education and ethnicity jointly, as well as age, and are carried out overall and by place of residence. The final part of the analysis consists of cross-tab tables that examine several fertility-relevant characteristics and how they vary by ethnic group and by education group.

\section{Results}

Ethnic Groups in the DRC

The DRC is an ethnic mosaic, with more than 300 distinct tribes. Some of these tribes are part of welldefined broad ethnic groups like the Bakongo. But in other cases, this is not so, and researchers seeking to study different ethnic groups are confronted with the challenge of categorizing the very many tribes into a manageable number of broader ethnic groups. The classic work that proposed aggregating the numerous tribes into a smaller number of "cultural regions" or (for the most part) broad ethnic groups was Jan Vansina's Introduction à l'ethnographie du Congo (1966). Vansina identified I5 distinct cultural regions in the country, and his classification scheme has been used by many researchers subsequently.

For the DHS, these tribes have been aggregated into nine different categories that correspond to Vansina's 15-group classification. For this paper, we analyze data on the seven groups for which there are substantial numbers of respondents in the DHS data, sufficient in number to allow us to calculate total fertility rates by ethnic group. These groups are the Bakongo, those from Bas-Kasai and Kwilu-Kwango (henceforth, Kwilu-Kwango ${ }^{+}$), those residing in the Cuvette Centrale, Ubangi and Itimbiri (Ubangi ${ }^{+}$), Uele and Lac Albert $\left(\right.$ Uele $\left.^{+}\right)$, Balese-Komo, Maniema, \& Kivu (Balese-Komo ${ }^{+}$), and those from Kasai, Katanga, and Tanganyika (Kasai ${ }^{+}$). These seven groups account for more than 98 percent of the sample of female DHS respondents, with the Kasai ${ }^{+}$ and the Balese-Komo ${ }^{+}$groups accounting for 25 and 20 percent of the total, respectively.

Table I, based on analysis of DHS sample respondents, shows that in 10 of the 11 provinces ${ }^{2}$, one or at most two broad ethnic groups predominate in any given province. The Bakongo group accounts for 95 percent of the sample from Kongo Central province (formerly Bas-Congo), the Balese-Komo ${ }^{+}$ group accounts for 94-98 percent of the sample from Maniema and North and South Kivu, the Kasai ${ }^{+}$ group represents 84 to 90 percent of the sample from Kasai-Oriental, Kasai-Occidental, and Katanga, the Bas-Kasai and Kwilu-Kwango group comprises 80 percent of the sample from Bandundu province, the $\mathrm{Uele}^{+}$group accounts for 70 percent of the sample from Orientale province, and the Ubangi ${ }^{+}$group composes almost 65 percent of the sample from Equateur province, with the remainder of the sample from the province consisting almost entirely of those from the Cuvette Centrale. Kinshasa is the exception: more than 30 percent of the sample from the city is made up of both Bakongo and Bas-Kasai/KwiluKwango people, and nearly another 20 percent are from the $\mathrm{Kasai}^{+}$group. Other groups are also lightly represented in the sample from the city. 
Table 1. Ethnic Group Composition of the Sample, Overall and by Province, 2013-14 DHS

\begin{tabular}{|c|c|c|c|c|c|c|c|c|c|}
\hline Province & $\begin{array}{l}\text { Bak- } \\
\text { ongo }\end{array}$ & $\begin{array}{l}\text { Kwilu- } \\
\text { Kwango }\end{array}$ & $\begin{array}{l}\text { Cuvette } \\
\text { Centrale }\end{array}$ & Ubangi $^{+}$ & $\mathrm{Uele}^{+}$ & $\begin{array}{l}\text { Balese- } \\
\text { Komo }^{+}\end{array}$ & Kasai $^{+}$ & Other & Total \\
\hline Kinshasa & 33 & 30 & 6 & 7 & 1 & 3 & 18 & 2 & 100 \\
\hline Bandundu & 1 & 80 & 18 & 0 & 0 & 0 & 0 & 0 & 100 \\
\hline Kongo Central & 95 & 2 & 0 & 0 & 0 & 0 & 0 & 2 & 100 \\
\hline Equateur & 1 & 0 & 34 & 64 & 0 & 0 & 0 & 1 & 100 \\
\hline Kasai-Oc. & 0 & 13 & 1 & 0 & 0 & 0 & 85 & 1 & 100 \\
\hline Kasai-Or. & 0 & 5 & 10 & 0 & 0 & 0 & 84 & 1 & 100 \\
\hline Katanga & 0 & 1 & 0 & 0 & 0 & 1 & 90 & 8 & 100 \\
\hline Maniema & 0 & 0 & 0 & 0 & 0 & 98 & 0 & 1 & 100 \\
\hline Nord Kivu & 1 & 1 & 0 & 0 & 2 & 94 & 1 & 1 & 100 \\
\hline Orientale & 0 & 0 & 1 & 16 & 70 & 10 & 1 & 1 & 100 \\
\hline Sud Kivu & 0 & 1 & 0 & 0 & 1 & 97 & 0 & 1 & 100 \\
\hline Total & 9 & 18 & 9 & 11 & 7 & 20 & 25 & 2 & 100 \\
\hline
\end{tabular}

Source: Analysis of the 2013-I4 DRC Demographic and Health Survey data.

Education, Ethnicity, and Fertility in the DRC as of 2014

Map 3 shows total fertility rates by province for the II provinces that existed in 2014. Kinshasa is the only

province with a TFR below 5 , and Bas-Congo and Orientale are the only other provinces with TFRs that do not exceed 6.

Map 3. Total Fertility Rates by Province, 2013-14

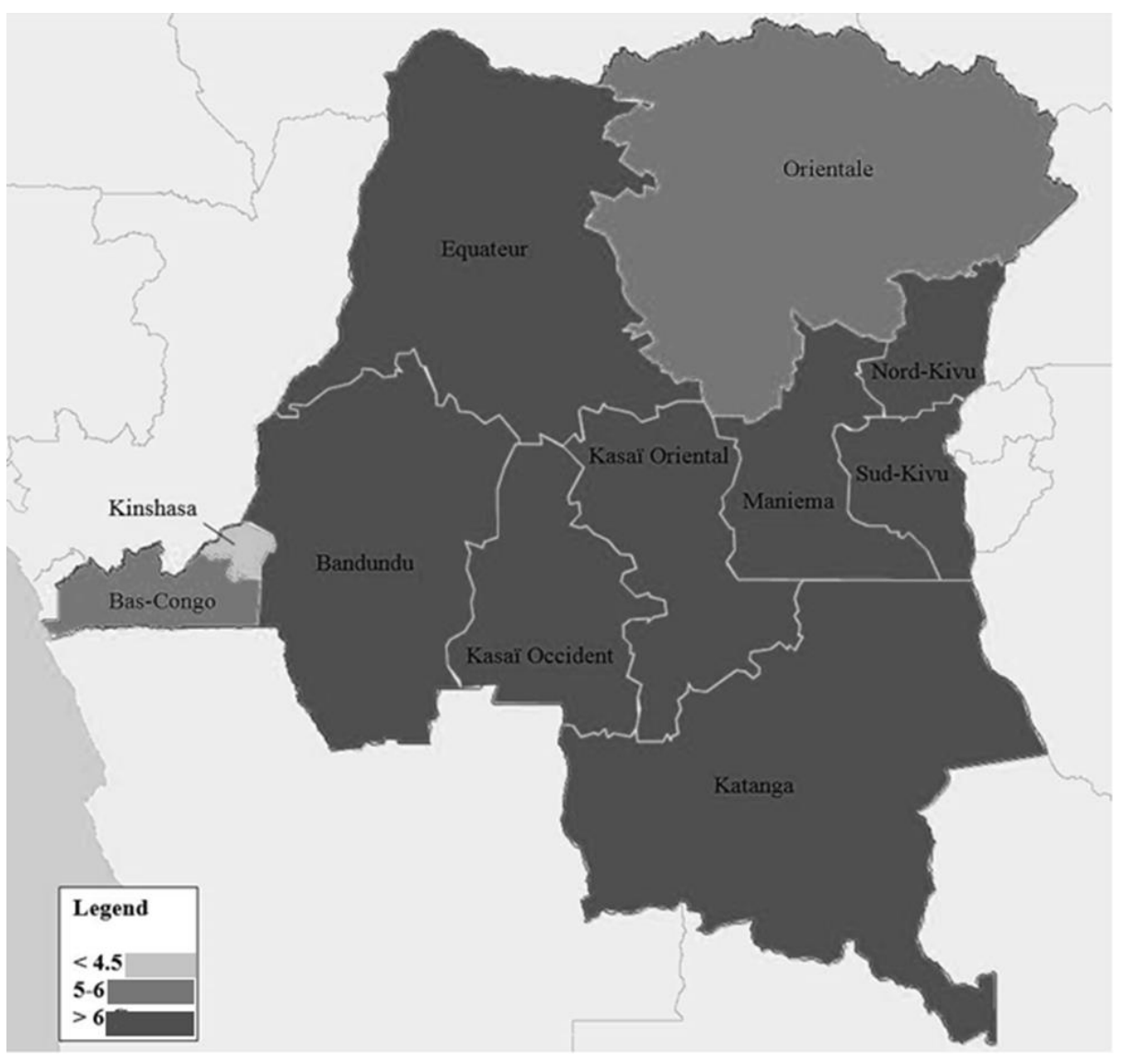


Map 4 shows TFRs for the 26 new provinces that came into being in mid-2015. Kinshasa remains the only low-fertility province. Only four other provinces have fertility that does not exceed 6.0: Kongo Central (the former Bas-Congo province), Mai-Ndombe, Haut-Uele, and Tshopo. Over all, four of the new provinces have TFRs of 8.0 or higher, and another eight provinces have TFRs between 7 and 8 .

Map 4. Total Fertility Rates in 2013-14, by New Province as of 2015

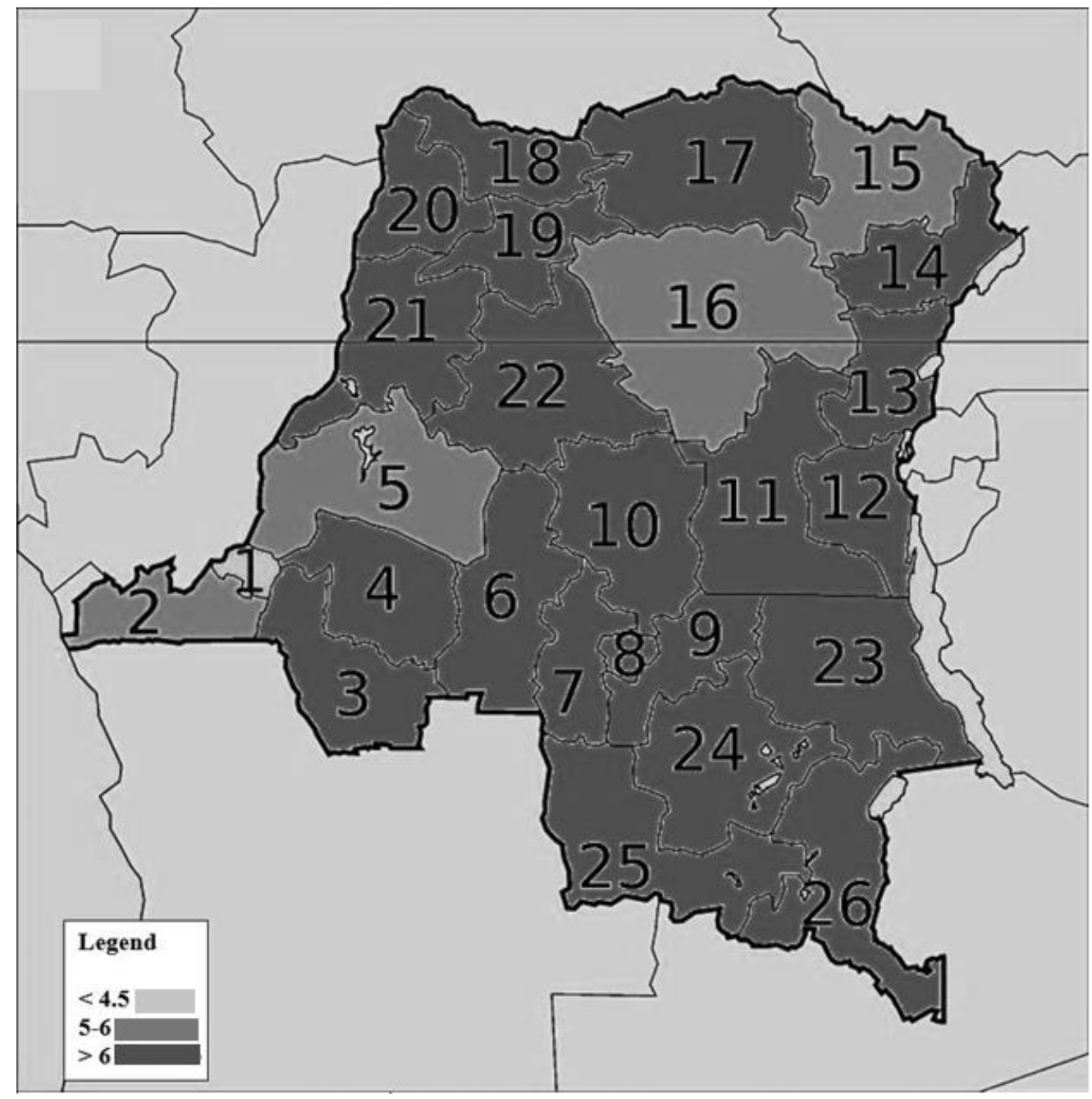

Table 2 shows the total fertility rates by ethnic group for the seven major ethnic groups, in total and separately for rural areas, urban places other than Kinshasa, and for Kinshasa. Over all, the Kasai ${ }^{+}$group has the highest fertility, with a national TFR of 7.4.
Also with relatively high fertility are the Balese$\mathrm{Komo}^{+}$and Ubangi ${ }^{+}$groups, with TFRs of 6.9 and 6.7, respectively. ${ }^{4}$ Bakongo women clearly had the lowest fertility overall, with a TFR of 5.0, and Uele ${ }^{+}$ women were next lowest with a TFR of 5.9 .

Table 2. Total Fertility Rates by Ethnic Group and by Place of Residence, 2013-14 DHS

\begin{tabular}{|l|c|c|c|c|}
\hline Ethnic Group & Total & Rural & Urban (not Kinshasa) & Kinshasa \\
\hline Bakongo & 5.0 & 7.4 & 4.0 & 3.6 \\
\hline Kwilu-Kwango $^{+}$ & 6.3 & 7.1 & 5.5 & 4.7 \\
\hline Cuvette Centrale $^{\text {Ubangi }^{+}}$ & 6.3 & 6.4 & 6.3 & 5.2 \\
\hline Uele $^{+}$ & 6.7 & 7.2 & 5.3 & 4.8 \\
\hline Balese-Komo $^{+}$ & 5.9 & 6.0 & 5.6 & $*$ \\
\hline Kasai $^{+}$ & 6.9 & 7.6 & 5.4 & 3.8 \\
\hline Total & 7.4 & 8.2 & 7.0 & 3.6 \\
\hline
\end{tabular}

* Insufficient number of cases to calculate a TFR.

Source: Analysis of the 2013-14 DRC Demographic and Health Survey data. 
Within each ethnic group, fertility is lowest in Kinshasa and highest in rural areas. TFRs in Kinshasa show a comparatively modest range, from 3.6 to 5.2 among the different ethnic groups. Over all, Kinshasa has substantially lower fertility than smaller urban places, where TFRs range from 4.0 to 7.0. Among some ethnic groups this difference between Kinshasa and other urban places is small (Bakongo and Ubangi ${ }^{+}$), and among the Kasai ${ }^{+}$group it is huge. Conversely, comparison of fertility between other urban places and rural areas, where TFRs range from 6.0 to 8.2, shows that the Cuvette Centrale and Uele $^{+}$groups have only small differences, while among the Bakongo women the difference is huge. Among rural residents, TFRs are above 7 except for those from the Cuvette Centrale and $\mathrm{Uele}^{+}$women, with TFRs of 6-6.4.

Total fertility rates by educational attainment are shown in Table 3 for seven groups of women, with a) no schooling, b) incomplete primary schooling, c) completed primary schooling (six years), d) low, e) medium, and $f$ ) high secondary education, and g) post-secondary education. Rates are shown for the country overall, and for rural areas, urban places other than Kinshasa, and Kinshasa. In total, peak fertility is among women with incomplete primary education, followed closely by those with no schooling and those with completed primary education. All three groups have TFRs in excess of seven. Fertility declines beginning with those with one or two years of secondary schooling, and following those with three or four years of secondary schooling, the declines widen as schooling increases. These results are consistent with those from previous studies in the DRC, both in Kinshasa (Shapiro and Tambashe, 2003) and outside of Kinshasa (SalaDiakanda, 1980), and elsewhere in sub-Saharan Africa (United Nations, 1995; Shapiro and Tenikue, 2017).

Table 3. Total Fertility Rates by Schooling and by Place of Residence, 2013-14 DHS

\begin{tabular}{|l|c|c|c|c|}
\hline Schooling (years) & Total & Rural & Urban (not Kinshasa) & Kinshasa \\
\hline 0 & 7.4 & 7.5 & 6.0 & a \\
\hline $1-5$ & 7.5 & 7.6 & 7.1 & 6.8 \\
\hline 6 & 7.2 & 7.6 & 6.8 & 5.3 \\
\hline $7-8$ & 6.6 & 6.8 & 6.7 & 5.4 \\
\hline $9-10$ & 6.1 & 6.7 & 6.4 & 4.8 \\
\hline $11-12$ & 4.7 & 6.1 & 4.8 & 3.6 \\
\hline $13-18$ & 2.9 & $\mathrm{a}$ & 3.2 & 2.5 \\
\hline Total & 6.6 & 7.3 & 6.0 & 4.2 \\
\hline
\end{tabular}

${ }^{\mathrm{a}}$ Inadequate sample size for calculation of a TFR.

Source: Analysis of the 2013-14 DRC Demographic and Health Survey data

When one considers fertility levels and differentials by place of residence, two key aspects emerge. First, fertility is considerably lower in Kinshasa than in other urban places, whose overall mean TFR of 6.0 is closer to average rural fertility than to the TFR in Kinshasa. This pattern is evident at each schooling level. Second, the sensitivity of fertility to education is greatest in Kinshasa and smallest in rural areas. In other urban places, a strong inverse association between education and fertility emerges only among those with at least upper-level secondary education.

In order to assess the net impact of both education and ethnicity on fertility, we have analyzed fertility in a multivariate framework, using micro data on female respondents from the 2013-14 DHS. The dependent variable is the number of children ever born. Independent variables include a set of dummy variables identifying women with different levels of schooling. Reflecting the differences observed in Table 3, these dummy variables entail a more refined set of distinctions than the none/primary/secondaryand-above trichotomy that is often used in fertility research controlling for women's education. This finer characterization of educational attainment has been found to yield suggestive evidence of nonlinearity in the relationship between education and fertility in Kinshasa, with the impact of education increasing as educational attainment increases, beginning at the lower secondary level (Shapiro and Tambashe, 2003); similar widening of fertility differentials with increased schooling has been found in a large number of countries in the region (United Nations, 1995; Shapiro, 2012; Shapiro and Tenikue, 2017). Women with I-6 years of primary school constitute the reference category. ${ }^{5}$ In addition; a set of dummy variables identifies the seven broadly defined ethnic groups in the DHS data, as well as a small residual "other ethnicity" category. These education and ethnicity variables are the focus of our analysis, and age and age squared as well as (in the regression for the entire country) dummy variables for residence in Kinshasa and in other urban places are included as control variables.

Analyses were carried out at multiple levels, as shown in Table 4. The first equation shows the coefficients for the entire sample, all women aged I5- 
49. All variables are highly significant except for other urban residents, and the $R^{2}$ equals 0.623 . The allnegative coefficients of the education dummy variables reveal that peak fertility is among women with primary schooling only, while both women with no schooling and those with low-level secondary schooling have slightly fewer numbers of children ever born, ceteris paribus. Then, as education increases, the magnitude of the corresponding reduction in number of children ever born increases, with substantial negative coefficients for women with advanced secondary or post-secondary schooling in particular.

Table 4. Children Ever Born Regressions, by Place of Residence, 2013-14 DHS

\begin{tabular}{|c|c|c|c|c|c|}
\hline \multicolumn{2}{|c|}{ Variable or parameter } & All Women & Rural & $\begin{array}{c}\text { Urban } \\
\text { Other than } \\
\text { Kinshasa })\end{array}$ & Kinshasa \\
\hline Age & Age & $0.479^{* *}$ & $0.526^{* *}$ & $0.455^{* *}$ & $0.225^{* *}$ \\
\hline & Age & $-0.0040^{* *}$ & $-0.0046^{* *}$ & $-0.0036^{* *}$ & -0.00081 \\
\hline Schooling & None & $-0.165^{* *}$ & $-0.184^{* *}$ & $-0.264^{* *}$ & 0.463 \\
\hline & Prim1-6 & - & - & - & - \\
\hline & Sec12 & $-0.220^{* *}$ & $-0.179^{* *}$ & $-0.232^{* *}$ & $-0.320^{*}$ \\
\hline & Sec34 & $-0.555^{* *}$ & $-0.559^{* *}$ & $-0.565^{* *}$ & $-0.625^{* *}$ \\
\hline & Sec56 & $-1.191^{* *}$ & $-1.015^{* *}$ & $-1.247^{* *}$ & $-1.218^{* *}$ \\
\hline & Univ & $-2.365^{* *}$ & $-2.544^{* *}$ & $-2.453^{* *}$ & $-2.152^{* *}$ \\
\hline Ethnic group & Bakongo & $-0.552^{* *}$ & $-0.285^{* *}$ & $-0.993^{* *}$ & $-0.366^{* *}$ \\
\hline & Kwilu-Kwango & $-0.420^{* *}$ & $-0.498^{* *}$ & $-0.391^{* *}$ & 0.010 \\
\hline & Cuvette Centr. & $-0.327^{* *}$ & $-0.373^{* *}$ & -0.173 & -0.046 \\
\hline & Ubangi $^{+}$ & $-0.348^{* *}$ & $-0.294^{* *}$ & $-0.564^{* *}$ & 0.068 \\
\hline & Uele & $-0.657^{* *}$ & $-0.672^{* *}$ & $-0.635^{* *}$ & -0.052 \\
\hline & Balese-Komo & $-0.184^{* *}$ & $-0.112^{*}$ & $-0.328^{* *}$ & -0.281 \\
\hline & Kasai $^{+}$ & - & - & - & - \\
\hline & Other & $-0.437^{* *}$ & $-0.595^{* *}$ & -0.234 & -0.175 \\
\hline Urban & Other Urban & -0.091 & - & - & - \\
\hline & Kinshasa & $-.554^{* *}$ & - & - & - \\
\hline Parameters & Constant & $-6.154^{* *}$ & $-6.947^{* *}$ & $-5.822^{* *}$ & $-2.625^{* *}$ \\
\hline & R ${ }^{2}$ & 0.623 & 0.615 & 0.642 & 0.568 \\
\hline & N & 18827 & 12000 & 5023 & 1804 \\
\hline
\end{tabular}

** coefficient significant at .01 level

* coefficient significant at .05 level

Source: Analysis of the 2013-14 DRC Demographic and Health Survey data.

The coefficients for the different ethnic groups show how the group in question compares to those from the reference group, Kasai/Katanga/Tanganyika, other things equal. The negative coefficients for all groups indicate that the Kasai ${ }^{+}$group has the highest fertility. Comparatively, the Uele ${ }^{+}$and Bakongo groups have the lowest fertility, other things equal. Fertility of the Balese-Komo ${ }^{+}$is only slightly below that of the $\mathrm{Kasai}^{+}$group, followed by those from the Cuvette Centrale, Ubangi ${ }^{+}$, and those from Kwilu or Kwango. These net differences by ethnicity are similar to those in the TFRs.

While the differences across ethnic groups are highly significant, the magnitudes of the coefficients are for the most part fairly modest, with a maximum absolute value of 0.66 . Compared to the coefficients for the education groups, and especially the two highest ones, this makes it clear that in general, fertility differences by ethnic group, other things equal, are smaller than fertility differences by educational attainment.

The coefficients on age and age squared signify that number of children ever born increases with age, but at a decreasing rate. Fertility of women from Kinshasa is significantly lower than that of rural women by more than half a child, other things equal, representing almost 18 percent of the mean value of 3.15 for the entire sample. In contrast, fertility of women from other urban places was not significantly different from that of rural women.

The next column of Table 4 shows the coefficients for the sample of rural women. As was the case for all

women, all coefficients are statistically significant, and the variables account for more than 60 percent of the variation in number of children ever born. The pattern of differences by educational attainment remains pretty much the same as with the full 
sample. With respect to fertility differences by ethnicity, note that the especially low fertility of Bakongo women is no longer present, reflecting the low fertility of urban Bakongo women already noted, while the Uele+ women emerge distinctly as the lowest fertility group in the rural DRC, other things equal. Otherwise, the fertility differences by ethnic group remained fairly similar to those from the full sample. Reflecting the higher fertility in rural places, the coefficients of age and age squared have increased in absolute value.

The counterpart to the rural estimates just discussed would be an equation for women in urban places. Such an equation shows educational differences in fertility similar to what we've already seen. Differences by ethnic group are a little more variable - urban Bakongo women have especially low numbers of children ever born. But this equation masks the reality that Kinshasa is a unique megalopolis in the DRC, where economic hardship as well as comparatively high women's education have been emphasized as contributing to the city's fertility decline since 1990 (e.g., see Romaniuk, 20II, Shapiro, 2015, and Shapiro et al., 2017). So instead we've divided up urban residents into two groups: those from everywhere except Kinshasa, and those from Kinshasa. Note that urban places other than Kinshasa are not only smaller, but also they are more likely to be ethnically more homogeneous (assuming that intraprovincial migration is more common than interprovincial migration) as compared to the melting pot of Kinshasa.

Column 3 of coefficients in Table 4 shows the results for urban places other than Kinshasa. Comparing these coefficients with those for all women and for rural women shows a very similar pattern of educational differences. With respect to variation in ethnic group differences, this is much more substantial. For some groups the differences with the $\mathrm{Kasai}^{+}$women have widened (Bakongo, Ubangi $^{+}$, Balese-Komo ${ }^{+}$), for others they've narrowed (Kwilu-Kwango, Cuvette Centrale), and in one case stayed about the same $\left(\mathrm{Uele}^{+}\right)$. Other things equal, Bakongo women have the lowest fertility for these urban places.

Finally, the last column of coefficients shows the results for Kinshasa. Women with no schooling (a very small group) are not significantly different from the reference group of women with primary schooling with respect to children ever born. Beyond that the pattern of education coefficients is familiar, with widening differentials as educational attainment increases, and the magnitudes of the differences are similar to those in the other samples. With respect to ethnic groups, Kinshasa is clearly unique: there is only one significant coefficient, for Bakongo women, and at a smaller level than for such women in other urban places. Hence, for the most part there are not significant differences in fertility across ethnic groups in Kinshasa, once age and education are taken into account. Reflecting the lower overall fertility in Kinshasa, the age coefficient is substantially smaller than in the other equations.

The results from Table 4 show three important aspects. First, the magnitudes of the coefficients for education are noticeably robust, regardless of place of residence. This is not the case for the coefficients of the ethnic group dummy variables. Second, in Kinshasa, with one exception, ethnic group differences in fertility are negligible. Elsewhere in the country, however, in both rural and urban places, there are significant fertility differences across ethnic groups, other things equal, with some variation by place of residence in the magnitudes of those differences. Third, the magnitudes of these fertility differences by ethnic group in rural and other urban places are comparatively small as compared to the magnitudes of the fertility differences by educational attainment. In sum, then, in Kinshasa education has replaced ethnicity as a factor influencing fertility; elsewhere in the country, both education and ethnicity influence fertility, but the importance of differences in education attainment is clearly dominant.

\section{Exploring Fertility Differences among the Ethnic Groups}

From our analyses of fertility by ethnicity, two groups stood out. The Bakongo women typically had the lowest fertility of any group, while the Kasai ${ }^{+}$women had the highest fertility, other things equal. Uele ${ }^{+}$ women also had low fertility ${ }^{6}$, while women from the Balese-Komo ${ }^{+}$group had comparatively high fertility. Multiple reasons may contribute to these differences in fertility. Table 5 shows the mean values by ethnic group for a number of different fertility-relevant characteristics and behaviors, and these data suggest that several factors are influencing the fertility differentials. 
Table 5. Some Fertility-Relevant Characteristics, by Ethnic Group, 2013-14 DHS

\begin{tabular}{|l|c|c|c|c|c|c|c|c|c|c|}
\hline Ethnic Group & $\begin{array}{c}\text { Ideal } \\
\text { \# of } \\
\text { child } \\
\text {-ren }\end{array}$ & $\begin{array}{c}\text { Age } \\
\text { at } \\
\text { first } \\
\text { sex }\end{array}$ & $\begin{array}{c}\text { Pct. } \\
\text { in } \\
\text { union }\end{array}$ & $\begin{array}{c}\text { Pct. } \\
\text { married }\end{array}$ & $\begin{array}{c}\text { Pct. } \\
\text { living } \\
\text { together }\end{array}$ & $\begin{array}{c}\text { Pct. } \\
\text { urban }\end{array}$ & $\begin{array}{c}\text { Pct. w/ } \\
\text { no } \\
\text { schooling }\end{array}$ & $\begin{array}{c}\text { Pct. w/ } \\
\text { sec+ } \\
\text { schooling }\end{array}$ & $\begin{array}{c}\text { Mean } \\
\text { years of } \\
\text { schooling }\end{array}$ & $\begin{array}{c}\text { Pct. } \\
\text { using } \\
\text { modern } \\
\text { contra- } \\
\text { ception }\end{array}$ \\
\hline Bakongo & 4.7 & 16.8 & 52 & 23 & 29 & 63 & 7 & 66 & 8.0 & 18 \\
\hline Kwilu-Kwan. $^{+}$ & 5.6 & 16.4 & 65 & 44 & 21 & 41 & 10 & 56 & 7.1 & 9 \\
\hline Cuvette Cent. $^{\text {Ubangi }}{ }^{+}$ & 5.9 & 15.2 & 69 & 50 & 20 & 23 & 13 & 48 & 6.3 & 6 \\
\hline Uele $^{+}$ & 5.8 & 15.7 & 70 & 41 & 29 & 24 & 24 & 32 & 4.8 & 5 \\
\hline Balese-Komo $^{+}$ & 5.4 & 15.4 & 64 & 35 & 29 & 23 & 18 & 32 & 5.0 & 5 \\
\hline Kasai $^{+}$ & 7.3 & 16.6 & 60 & 44 & 16 & 33 & 24 & 39 & 5.4 & 9 \\
\hline Total & 6.1 & 16.7 & 67 & 63 & 4 & 47 & 14 & 45 & 6.2 & 6 \\
\hline
\end{tabular}

Source: Analysis of the 2013-14 DRC Demographic and Health Survey data.

The mean value of the ideal number of children for those women who gave a quantitative response was 6.I. For this indicator of demand for children, the $\mathrm{Kasai}^{+}$women had the highest value by far, and the Bakongo women had the lowest value. The simple correlation between the ideal number of children (from Table 5) and the TFR (from Table 2) exceeds +0.9 . Hence, variations in ideal number of children appear to correspond well to the variations in fertility. At the same time, comparison of ideal number of children with actual fertility shows that the latter exceeds the former for each ethnic group. On average the divergence is half a child, and ranges from 0.1 to 0.9 children. The existence of actual fertility consistently in excess of ideal number of children is suggestive of the presence of a pervasive unmet need for contraception, which is estimated at nearly 28 percent (for both spacing and limiting) among women in union and 43 percent for women not in union but sexually active (Ministère du Plan et al., 20|4).

Mean age at the onset of sexual activity is highest for Bakongo women, but it is second highest for $\mathrm{Kasai}^{+}$women. This factor is essentially uncorrelated with the TFRs by ethnic group.

Three columns of the table pertain to being in union. The first of these columns shows the overall percentage of women in union in each group, and the next two columns break that total group into those who reported being married and those who indicated that they were living together as if married (i.e., cohabiting). The data here suggest that the proximate determinant of union status is an important contributor to the observed fertility differences by ethnic group. Most notably, Bakongo women have the lowest overall percentage of women in union, while $\mathrm{Kasai}^{+}$women have the highest percentage married by far, and very few cohabiting. Indeed, among Bakongo women in union, those reporting as being married are a minority - the only ethnic group for which this is the case. This unique characteristic is worth teasing out the root causes. Since women who are married typically have higher fertility than those who are cohabiting ${ }^{7}$, these differences in union status clearly contribute to the low Bakongo fertility and the high Kasai ${ }^{+}$fertility.

More than 60 percent of Bakongo women are urban residents; they are the only group that is predominantly urban in the DHS data. At the same time, the second-most urbanized group is the Kasai ${ }^{+}$ women. And apart from the highly urbanized lowfertility Bakongo women, there is actually a positive correlation between the percentage urban and the TFR among the other six ethnic groups.

With respect to educational attainment, regardless of the measure considered, Bakongo women are clearly those with the most schooling. They are least likely to have never gone to school, most likely to have reached secondary school, and their mean years of schooling are nearly a year greater than that of the second-highest group, and nearly two years higher than the national average. This is clearly an important factor contributing to the low fertility of Bakongo women.

Finally, almost one in five Bakongo women in union uses modern contraception, twice the rate and more of the other ethnic groups. As we'll see below, in part this reflects the higher educational attainment of these women. In any case, greater use of modern contraception is an additional factor contributing to the low fertility of Bakongo women.

\section{Exploring Fertility Differences Among the Education Groups}

This sub-section parallels the preceding one: we examine various characteristics and behaviors that influence fertility, and how they vary across education groups, with a view to understanding the sources of the fertility differences by educational attainment. The relevant data, for the same variables that were in 
Table 5 except for those pertaining to education, are in Table 6.

Table 6. Some Fertility-Relevant Characteristics, by Education Group, 2013-14 DHS

\begin{tabular}{|l|c|c|c|c|c|c|c|}
\hline Years of schooling & $\begin{array}{c}\text { Ideal\# } \\
\text { of } \\
\text { child- } \\
\text { ren }\end{array}$ & $\begin{array}{c}\text { Age at } \\
\text { first } \\
\text { sex }\end{array}$ & $\begin{array}{c}\text { Pct. in } \\
\text { union }\end{array}$ & $\begin{array}{c}\text { Pct. } \\
\text { married }\end{array}$ & $\begin{array}{c}\text { Pct. living } \\
\text { together }\end{array}$ & $\begin{array}{c}\text { Pct. } \\
\text { urban }\end{array}$ & $\begin{array}{c}\text { Pct. using modern } \\
\text { contraception }^{\text {a }}\end{array}$ \\
\hline 0 & 7.2 & 16.2 & 80 & 61 & 19 & 9 & 4 \\
\hline $1-5$ & 6.7 & 15.8 & 73 & 53 & 20 & 19 & 4 \\
\hline 6 & 6.4 & 15.8 & 67 & 49 & 18 & 32 & 6 \\
\hline $7-8$ & 5.8 & 15.9 & 56 & 39 & 17 & 44 & 10 \\
\hline $9-10$ & 5.4 & 16.5 & 54 & 37 & 17 & 63 & 14 \\
\hline $11-12$ & 5.0 & 17.3 & 54 & 37 & 17 & 75 & 16 \\
\hline $13^{+}$ & 4.2 & 19.1 & 36 & 29 & 6 & 96 & 18 \\
\hline Total & 6.1 & 16.2 & 64 & 47 & 18 & 38 & 8 \\
\hline
\end{tabular}

${ }^{\mathrm{a}}$ Women in union.

Source: Analysis of the 2013-14 DRC Demographic and Health Survey data.

Ideal number of children declines monotonically with years of schooling, by a total of three children from the lowest to the highest education level. Only at the secondary level, however, does it fall below six, and only at the upper secondary level does it reach five. The correlation between ideal number of children and the TFR exceeds +0.9 . Hence, ideal number of children clearly helps explain the education differences in fertility.

Age at first sex is about 16 up through the group with 7 or 8 years of schooling, then rises among the three groups with the most schooling, with an especially large jump, to more than 19 years, for the group with postsecondary schooling. That and the upper secondary group are the only ones with distinctly higher age at first sex, which presumably contributes to delay in childbearing (Shapiro and Tambashe, 2003).

The percentage of women in union declines substantially as years of schooling increase, and proportionately, more than twice as many women with no schooling are married than are women with postsecondary schooling. In addition, when we look at type of union, it is clear that the decline in the percentage of women in union as schooling increases is driven by the decline in the proportion of those who are married; except for those with postsecondary schooling, 17-20 percent of women in union in each education group are cohabiting. This figure drops sharply among those with postsecondary schooling, and indeed they are the group with the highest percentage of unions being marriages.

Place of residence is strongly and systematically linked to educational attainment: the percentage urban rises sharply as one moves across the education groups. At the extremes, more than 90 percent of women with no schooling are in rural areas, while 96 percent of those with postsecondary education are in urban places.

And finally, use of modern contraception is clearly positively related to educational attainment. This indicates that contraceptive use is also a contributing factor to the education differentials in fertility. However, since the overall level of contraceptive use among women in union is less than 20 percent for the group with the most schooling, this is likely only a modest contributing factor at best.

\section{Summary, Discussion, and Conclusions}

This paper has examined fertility in the Democratic Republic of the Congo going back about 60 years, with the objective of determining if the supplanting of ethnicity by women's education as an important factor influencing fertility that had previously been observed for Kinshasa was true more broadly in the country at large. What we found in this regard is that while in Kinshasa fertility differentials by ethnicity are almost non-existent, once one controls for schooling and age, elsewhere in the country such differentials are present, in both urban and rural places. At the same time, fertility differentials by ethnicity are generally smaller than the differentials by educational attainment that are evident. Hence, for the country as a whole, or more precisely, outside of Kinshasa, while ethnicity has not disappeared as a factor relevant to fertility, it has clearly been surpassed in importance by women's education.

These findings regarding ethnicity appear to be more in sync with the social characteristics hypothesis in cosmopolitan Kinshasa, and with the cultural 
hypothesis elsewhere in the rest of the country, where the lives of women in the different ethnic groups are presumably still structured differently and under stronger social control as compared to those of their counterparts in the capital. The broader implication of this is that even in Kinshasa, fertility transition is likely to proceed differently for women in different ethnic groups, with the Bakongo women - with higher schooling, lower entry to union and especially marriage, and higher contraceptive use leading the way.

A second major finding of this paper is that place of residence matters. We carried out analyses separately for Kinshasa, other urban centers, and rural places, and results vary, sometimes considerably, by place of residence. While in general fertility declines as education increases beyond the primary level, the TFRs by educational attainment and place of residence jointly (Table 3 ) suggest that this schooling effect is largest in Kinshasa, and much more modest in rural areas.

Over all, the low fertility in Kinshasa, high fertility in rural areas, and intermediate fertility in smaller urban places (albeit closer to rural fertility than to Kinshasa fertility) is consistent with the notion of the three-stage process of fertility decline in the region posited by Shapiro and Tambashe (2002) and found as well by Shapiro and Tenikue (2017). In this threestage process, fertility decline begins in urban centers, spreads to rural areas, and eventually becomes more rapid in rural places after urban fertility has reached low levels. What is added here is the distinction between capital cities and other urban places, with fertility decline initiated in the capitals.

We also have categorized educational attainment in much more detail than the often-utilized trichotomy (none/primary/secondary + ), using seven categories. Results show consistent differences in fertility among these different groups. In addition, based on this more detailed categorization, the results showed that fertility declines with education tend to increase in magnitude as the years of educational attainment increase. Given that women's schooling beyond primary education remains very low both in rural and other urban settings, with modern contraceptive use failing to take hold throughout the country, the DRC has a long way to go before experiencing any national fertility decline.

We note that, apart from Table 4, the comparisons of differences by ethnicity and by schooling have been made using simple descriptive tables, without taking account of other relevant factors. Our next step in this research, then, is to examine the different characteristics and behaviors of interest contributing to these fertility differences in a multivariate framework, so as to isolate the http://aps.journals.ac.za differences associated with ethnicity and education, after controlling for other relevant factors (e.g., age).

Finally, another finding from this paper is that the demand for children (as measured by ideal or desired number of children) tends to be below actual fertility. This level of excess fertility is conceivably an expression of unmet need for contraception, which in fact has been estimated to be high in most West and Central African countries. The situation is further compounded by the fact that desired number of children, though lower than actual fertility, is more than twice the level of replacement fertility, even for the best-educated segment of women who typically lead the way as reproductive behavior innovators. As reducing desired number of children is viewed as a necessary but not a sufficient condition to bring down actual fertility (Muhoza et al., 20/4), a major implication of our findings here is a call for concerted, multipronged program efforts aiming at promoting a smaller family size of about three and addressing the root causes of the high level of unmet need for contraception across the board.

More broadly, if the DRC wishes to stimulate more rapid fertility decline so as to reap any ensuing demographic dividend and stimulate more rapid socioeconomic development, policies and programs that serve to quicken the pace of increase of women's educational attainment are highly desirable. This is especially the case for enhancing access to secondary schooling, and particularly in rural areas. Increased investment in women's schooling will be expensive, but will have important demographic payoffs in the long term.

\section{Notes}

I The Ubangi group, with especially low fertility in Kinshasa in 1955, did not mirror the fertility of this group outside of Kinshasa, which was not especially low. This might perhaps reflect a comparatively small sample size in the capital.

2 On June 30, 2015, pursuant to the DRC's Constitution, a political, administrative, and territorial restructuring of the country took place, and in place of the previous II provinces there are now 26 provinces. In the analyses of recent DHS data in this paper, we refer primarily to the II provinces that were in existence when the surveys were taken, although we do provide a map showing fertility as of 2013-14 in the 26 new provinces.

${ }^{3}$ Appendix Table I shows where the members of the different ethnic groups live. In some cases, they are highly concentrated in a single province (this is especially the case for the Uele ${ }^{+}$group, and largely the case for the Kwilu-Kwango ${ }^{+}$and Ubangi ${ }^{+}$ women), while in others they are divided between two provinces (Bakongo, in Kongo Central, and - 
with 45 percent of all Bakongo women - in Kinshasa; and Cuvette Centrale in Equateur and northern Bandundu); or three provinces (the Kasai ${ }^{+}$group, in the two Kasais and Katanga; Balese-Komo ${ }^{+}$, in Maniema and North and South Kivu).

${ }^{4}$ The Balese-Komo ${ }^{+}$group, in Maniema and the Kivus, included many traditional pastoralists who did not practice extended breastfeeding nor long periods of postpartum abstinence, accounting for their high fertility.

${ }^{5}$ In comparison with Table 3 , in Table 4 we combine the incomplete primary and completed primary groups. These two groups have similar fertility except in Kinshasa, and combining them gives us a larger reference group for the regressions.

${ }^{6}$ The Uele group in Orientale Province was the ethnic group that experienced the lowest fertility in the 1950s. Romaniuk (2013) has argued that the comparatively low fertility of this group at present likely reflects a continued, albeit reduced, presence of STls in the region.

${ }^{7}$ A regression similar to the first equation in Table 4, but with additional variables for type of union, shows that other things equal, the number of children ever born is lower for cohabiting women as opposed to married women by 0.4 children.

\section{Acknowledgement}

We gratefully acknowledge excellent research assistance provided by Kevin Burke and Eleanor Tsai, computational assistance from Tesfayi Gebreselassie, and helpful comments from Anatole Romaniuk and three reviewers. Support from the Bates White Research Experiences for Undergraduates Program of the Penn State Department of Economics is also acknowledged. Responsibility for the contents of this paper rests solely with the authors.

\section{References}

Bauni, Evasius, Wanjiru Gichuhi, and Samson Wasao. 1999. "Ethnicity and fertility in Kenya." APHRC Working Paper No. II.

Bongaarts, John. 2010. "The causes of educational differences in fertility in Sub-Saharan Africa." Vienna Yearbook of Population Research 2010 (8): 3I-50.

Brunette, Tracy Ann. 1996. "Ethnicity and fertility in West Africa: A modified proximate determinants analysis among ethnic groupings in Nigeria and Senegal." Paper presented at the Annual Meeting of the Population Association of America, New Orleans, LA.

Castro Martin, Teresa. 1995. "Women's Education and Fertility: Results from 26 Demographic and Health Surveys." Studies in Family Planning. 26(4): 187-202
Cleland, John and Shireen Jejeebhoy. 1996. "Maternal Schooling and Fertility: Evidence from Censuses and Surveys." In Roger Jeffery and Alaka M. Basu, eds. Girls' Schooling, Women's Autonomy and Fertility Change in South Asia. Thousand Oaks, CA: Sage Publication, pp. 72-106.

Cochrane, Susan Hill. 1979. Fertility and Education: What Do We Really Know? World Bank Staff Occasional Papers No. 26. Baltimore, MD: The Johns Hopkins University Press.

Davis, Kingsley and Judith Blake. 1956. "Social structure and fertility: An analytic framework." Economic Development and Cultural Change, 4(4) $211-235$

Easterlin, Richard A. 1975. "An Economic Framework for Fertility Analysis." Studies in Family Planning, 6(I): 54-63.

Easterlin, Richard A. and Eileen M. Crimmins. 1985. The Fertility Revolution: A Supply-Demand Analysis. Chicago: University of Chicago Press.

Garenne, Michel and Julien Zwang. 2006. Premarital Fertility and Ethnicity in Africa. DHS Comparative Reports No. 13. Macro International: Calverton, MD.

Gastardo-Conaco, Cecelia and Pilar Ramos-jimenez, with Ruth Barniego. 1986. Ethnicity and Fertility in the Philippines. Singapore: Institute of Southeast Asian Studies.

Jayne, Susan H. 1997. "What more do we need to know about education and child survival?" Paper presented at the Annual Meeting of the Population Association of America, Washington, D.C.

Jejeebhoy, Shireen J. 1995. Women's Education, Autonomy, and Reproductive Behavior: Experience from Developing Countries. Oxford: Clarendon Press.

Kim, Jungho. 2016. "Female education and its impact on fertility - The Relationship is More Complex than One May Think." IZA World of Labor. http://wol.iza.org/articles/female-education-andits-impact-on-fertility.pdf. Accessed on 31 December 2016.

Kollehlon, Konia T. 1989. "Ethnicity and fertility in Liberia: A test of the minority group status hypothesis." Social Biology, 36(I \& 2): 67-8I.

Kritz, Mary M. and Pauline Makinwa-Adebusoye. 1994. "Ethnic Differences in Demand for Children in Nigeria: The Role of Women's Control." Population and Development Program, Working Paper No. 94.07. Cornell University: Ithaca, NY.

Kritz, Mary M. and Pauline Makinwa-Adebusoye. 1998. "Couple Differences in Family Planning Approval and Sources of Variation: The Role of Ethnicity and Wife's Authority in Nigeria." Population and Development Program, Working Paper No. 98.07. Cornell University: Ithaca, NY. http://aps.journals.ac.za 
Ministère du Plan et Suivi de la Mise en œuvre de la Révolution de la Modernité (MPSMRM), Ministère de la Santé Publique (MSP) and ICF International. 2014. Enquête Démographique et de Santé en République Démocratique du Congo 20I3-20I4. Rockville, Maryland, USA: MPSMRM, MSP and ICF International.

Mogford, Liz. 2004. "Structural Determinants of Child Mortality in Sub-Saharan Africa: A Crossnational Study of Economic and Social Influences from 1970 to 1997." Social Biology. 5I(3-4): 94120.

Muhoza, Dieudonné Ndaruhuye, Annelet Broekhuis, and Pieter Hooimeijer. 2014. "Variations in Desired Family Size and Excess Fertility in East Africa." International Journal of Population Research. 2014: I-II. https://www.hindawi.com/journals/iipr/20I4/4860 $79 /$

Nahmias, Petra. 2007. "The Importance of Ethnicity: Fertility and Ethnicity in West Africa." Paper presented at the Annual Meeting of the Population Association of America, New York, NY.

République du Zaïre, Societa d'Igegneria e Consulenza Attivita Industriali, and Department of Demography, Catholic University of Louvain. 1978. Etude démographique de l'ouest du Zaire. Vol. 3, Mouvement de la population : Nuptialité, fécondité, mortalité, migrations. Louvain-laNeuve, Belgium: Université Catholique de Louvain.

Retel-Laurentin, Anne. 1974. Infécondité en Afrique noire : Maladies et conséquences sociales. Paris: Masson \& Co.

Romaniuk, Anatole. 196I. Aspect démographique de la stérilité des femmes congolaises. Institut de Recherches Economiques et Sociales, Studia Universitatis, Lovanium. Leopoldville : Editions de l'Université Léopoldville.

Romaniuk, Anatole. 1967. La Fécondité des populations congolaises. Paris: Mouton.

Romaniuk, Anatole. 1968. "The Demography of the Democratic Republic of the Congo." In William Brass et al., The Demography of Tropical Africa, pp. 24I-34I. Princeton: Princeton University Press.

Romaniuk, Anatole. 20II. "Persistence of High Fertility in Tropical Africa: The Case of the Democratic Republic of the Congo." Population and Development Review 37 (I): I-28.

Romaniuk, Anatole. 2013. "La démographie de la RD du Congo sous le régime du colonialisme mercantile belge, 1885-1940: un cas de dépopulation pour cause de dénatalité d'origine pathologique." Paper presented at the XXVII
International Union for the Scientific Study of Population International Population Conference, 26-3I August, Busan, South Korea.

Sala-Diakanda, Mpembele. 1980. Approche ethnique des phénomènes démographiques: Le Cas du Zairre. Louvain-la-Neuve, Belgium: Cabay Librairie-Editeur S.A., for Département de Démographie, Université Catholique de Louvain.

Shapiro, David. 1996. "Fertility decline in Kinshasa." Population Studies 50 (I): 89-I03.

Shapiro, David. 2010. "Ongoing Fertility Transition in Kinshasa: Evidence from the 2007 DHS." Paper presented at the Annual Meeting of the Population Association of America, Dallas, TX.

Shapiro, David. 2012. "Women's education and fertility transition in sub-Saharan Africa." Vienna Yearbook of Population Research 2012 (vol. I0): 9-30.

Shapiro, David. 2015. "Enduring Economic Hardship, Women's Education, Marriage, and Fertility Transition in Kinshasa," Journal of Biosocial Science 47(2): 258-274.

Shapiro, David and Tesfayi Gebreselassie. 2014. "Marriage in Sub-Saharan Africa: Trends, Determinants, and Consequences." Population Research and Policy Review, April 20I4, 33(2): 229-255.

Shapiro, David and B. Oleko Tambashe. 2002. "Fertility Transition in Urban and Rural SubSaharan Africa: Preliminary Evidence of a ThreeStage Process." Journal of African Policy Studies, 8(2\&3): 103-127.

Shapiro, David and B. Oleko Tambashe. 2003. Kinshasa in Transition: Women's Education, Employment, and Fertility. Chicago: University of Chicago Press.

Shapiro, David, Basile O. Tambashe, and Anatole Romaniuk. Forthcoming, 2017. "The Third Biggest African Country: The Democratic Republic of the Congo." Ch. 5 in Hans Groth and John F. May, eds., Africa's Population: In Search of a Demographic Dividend. Dordrecht, The Netherlands: Springer.

Shapiro, David and Michel Tenikue. 2017. "Women's Education, Infant and Child Mortality, and Fertility Decline in Urban and Rural Sub-Saharan Africa." Working paper.

Tabutin, Dominique. 1982. "Evolution régionale de la fécondité dans l'ouest du Zaïre." Population 37(I): 29-50.

Tabutin, Dominique and Eliwo Akoto. 1992. "Socioeconomic and Cultural Differentials in the Mortality of Sub-Saharan Africa." In Etienne van de Walle, Gilles Pison, and Mpembele SalaDiakanda, eds. Mortality and Society in Sub- 
Saharan Africa. Oxford: Clarendon Press, pp. 3264.

Tambashe, B. Oleko. 1984. Niveau et corrélats de la fécondité des mariages à Kinshasa : Examen par les variables intermédiaires. Louvain-la-Neuve, Belgium : Cabay Libraire-Editeur.

Tan, Mely and Budi Soeradji, 1986. Ethnicity and Fertility in Indonesia. Singapore: Institute of Southeast Asian Studies.

United Nations. 1995. Women's Education and Fertility Behaviour: Recent Evidence from the Demographic and Health Surveys. New York:
Population Division, Department for Economic and Social Information Analysis.

United Nations, Department of Economic and Social Affairs, Population Division. 2015. World Population Prospects: The 2015 Revision, DVD Edition.

Vansina, Jan. 1966. Introduction à l'ethnographie du Congo. Kinshasa : Editions Universitaires du Congo.

Westoff, Charles F., Kristin Bietsch, and Dawn Koffman. 2013. Indicators of Trends in Fertility in Sub-Saharan Africa. DHS Analytical Studies No. 34. Calverton, MD, USA: ICF International.

Table A-1. Province of Residence, by Major Ethnic Group, DHS Survey Respondents (percentage distributions)

\begin{tabular}{|c|c|c|c|c|c|c|c|c|}
\hline Province & Bakongo & $\begin{array}{l}\text { Kwilu- } \\
\text { Kwango }^{+}\end{array}$ & $\begin{array}{l}\text { Cuvette } \\
\text { Centrale }\end{array}$ & Ubangi $^{+}$ & $\mathrm{Uele}^{+}$ & $\begin{array}{l}\text { Balese- } \\
\text { Komo }^{+}\end{array}$ & $\mathrm{Kasai}^{+}$ & Total \\
\hline Kinshasa & 45 & 20 & 8 & 8 & 2 & 2 & 9 & 12 \\
\hline Bandundu & 3 & 71 & 31 & 0 & 0 & 0 & 0 & 16 \\
\hline Kongo Central & 50 & 1 & 0 & 0 & 0 & 0 & 0 & 5 \\
\hline Equateur & 1 & 0 & 49 & 77 & 0 & 0 & 0 & 13 \\
\hline Kasai-Oc. & 0 & 5 & 0 & 0 & 0 & 0 & 22 & 6 \\
\hline Kasai-Or. & 0 & 3 & 10 & 0 & 0 & 0 & 33 & 10 \\
\hline Katanga & 0 & 0 & 0 & 0 & 0 & 1 & 35 & 10 \\
\hline Maniema & 0 & 0 & 0 & 0 & 0 & 15 & 0 & 3 \\
\hline Nord Kivu & 1 & 0 & 0 & 0 & 2 & 41 & 0 & 9 \\
\hline Orientale & 0 & 0 & 1 & 15 & 95 & 5 & 0 & 10 \\
\hline Sud Kivu & 0 & 0 & 0 & 0 & 1 & 36 & 0 & 7 \\
\hline Total & 100 & 100 & 100 & 100 & 100 & 100 & 100 & 100 \\
\hline
\end{tabular}

Source: Analysis of Demographic and Health Survey data from the 2013-14 survey in the DRC. 